\title{
SOEP
}

SOEPpapers

SOEPpapers
on Multidisciplinary Panel Data Research

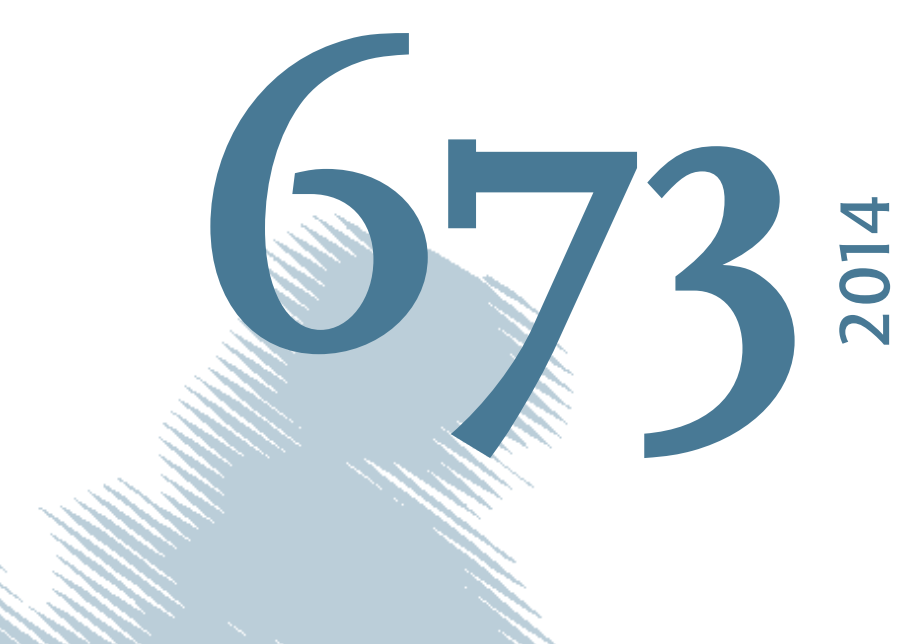

\section{Do Acquaintances and Friends Make Us Learn? \\ Social Capital and Lifelong Learning in Germany}




\section{SOEPpapers on Multidisciplinary Panel Data Research}

at DIW Berlin

This series presents research findings based either directly on data from the German SocioEconomic Panel Study (SOEP) or using SOEP data as part of an internationally comparable data set (e.g. CNEF, ECHP, LIS, LWS, CHER/PACO). SOEP is a truly multidisciplinary household panel study covering a wide range of social and behavioral sciences: economics, sociology, psychology, survey methodology, econometrics and applied statistics, educational science, political science, public health, behavioral genetics, demography, geography, and sport science.

The decision to publish a submission in SOEPpapers is made by a board of editors chosen by the DIW Berlin to represent the wide range of disciplines covered by SOEP. There is no external referee process and papers are either accepted or rejected without revision. Papers appear in this series as works in progress and may also appear elsewhere. They often represent preliminary studies and are circulated to encourage discussion. Citation of such a paper should account for its provisional character. A revised version may be requested from the author directly.

Any opinions expressed in this series are those of the author(s) and not those of DIW Berlin. Research disseminated by DIW Berlin may include views on public policy issues, but the institute itself takes no institutional policy positions.

The SOEPpapers are available at

http://www.diw.de/soeppapers

\section{Editors:}

Jürgen Schupp (Sociology)

Gert G. Wagner (Social Sciences, Vice Dean DIW Graduate Center)

Conchita D'Ambrosio (Public Economics)

Denis Gerstorf (Psychology, DIW Research Director)

Elke Holst (Gender Studies, DIW Research Director)

Frauke Kreuter (Survey Methodology, DIW Research Professor)

Martin Kroh (Political Science and Survey Methodology)

Frieder R. Lang (Psychology, DIW Research Professor)

Henning Lohmann (Sociology, DIW Research Professor)

Jörg-Peter Schräpler (Survey Methodology, DIW Research Professor)

Thomas Siedler (Empirical Economics)

C. Katharina Spieß (Empirical Economics and Educational Science)

ISSN: 1864-6689 (online)

German Socio-Economic Panel Study (SOEP)

DIW Berlin

Mohrenstrasse 58

10117 Berlin, Germany

Contact: Uta Rahmann | soeppapers@diw.de 


\title{
Do Acquaintances and Friends Make Us Learn? \\ Social Capital and Lifelong Learning in Germany
}

\author{
Anna-Elisabeth Thum*and Miroslav Beblavy ${ }^{\dagger}$
}

July 17,2014

\begin{abstract}
This paper examines the relationship between social capital and adult learning. We test this association empirically using measures of various types of social capital and adult learning based on the German Socioeconomic Panel. We use predetermined measures of social capital to exclude social skills or friends encountered during the adult education class. Fixed effects for latent underlying factors such as deep personality traits and instrumental variables account for changing personality traits. We find that most of our social capital measures have a significant and positive impact on the probabilities for investing in various types of adult learning. The size of the effect varies across the different measures between increasing the probability of participating in adult learning by $0.04 \%$ to increasing the probability by $17 \%$. We find evidence that acquaintances are more likely to increase participation in adult learning than friends.
\end{abstract}

\section{Introduction}

Friends, colleagues, acquaintances or our social network play a crucial role in our lives and often for our choices. They may influence our education decisions as well as our job choices and opportunities. Group or peer pressure to do well in life may arise in a certain social environment or a supportive environment may encourage us to make choices that increase our educational attainment or our labour market outcomes. A social network can transmit certain values and beliefs and it may act as a platform for passing important information by the means of word-of-mouth. Furthermore, being more sociable or having a sense of reciprocity may have a positive effect on our chances in life. All these examples show that social capital plays a role for what we are ready to invest in learning. However, forms of social capital can also be a substitute for efforts targeted towards educational attainment or success on the labour market: social capital can be a compensation for not having the necessary educational attainment for obtaining a specific job.

*European Commission and Centre for European Policy Studies

${ }^{\dagger}$ Center for European Policy Studies and Comenius University Bratislava 
In this paper we are interested in the role social capital plays for adult learning ${ }^{1}$ and in which type of social capital is likely to be the most important to promote adult learning activities in Germany. We define adult learning as the set of activities of an adult to improve knowledge, skills and competences ${ }^{2}$. To our knowledge it is the first paper that tests empirically the effect of different types of social capital on adult learning. With the rise of the knowledge-based economy human capital becomes more important: innovation becomes a key economic asset and information technologies of growing complexity need to be understood by those who operate them. Yet it is hard to motivate adults to invest time and effort into learning activities and it is a challenge for policy makers to increase the rate of participation in adult learning. We aim to show that social capital - the right social environment, the perceived importance of social activities or just the fact of having friends who might induce the feeling of wanting to learn - can have an influence on learning activities. Knowledge and an empirical demonstration of such a relationship could be useful for policy makers when designing "lifelong learning policies": taking into account the relationship between social capital and adult learning could make them realize that constructing an institution providing lifelong learning in a neighborhood with generally uneducated individuals is less likely to be a successful institution than in a more mixed neighborhood. Furthermore, we can show that it is not only one type of social capital that matters for an increase in learning activities: social capital can increase learning through various different channels. The effect of word-of-mouth and that of a supportive environment is just as important as a perceived importance of being socially active.

The importance of acknowledging and studying alternative potential determinants of adult learning to the traditional ones ${ }^{3}$ is being increasingly recognized. Brunello and Schlotter (2011) note that both economists and the European Union identify the importance of cognitive competencies and skills, but that they often do not take into consideration that other abilities somewhat linked to cognitive skills are possibly just as important. These non-cognitive abilities including personality traits can be for instance social competences, motivation and entrepreneurship. We interpret social competences as an underlying personality trait which makes social capital more or less likely. In the same light of underlining the importance of non-cognitive skills, Heckman (2000) argues that 'the preoccupation with cognition and academic 'smarts' as measured by test scores to the exclusion of social adaptability and motivation causes a serious bias in the evaluation of many human capital interventions'. Among EU policy makers the topic also gains in importance: the European Council identifies a set of key competencies by means of the 'European Framework for Key Competencies for Lifelong Learning' (2006), which include both cognitive and non-cognitive skills: communication in the mother tongue, communication in foreign languages, mathematical competence and basic competencies in science and technology, digital competence, learning to learn, social and civic competencies, sense of initiative and entrepreneurship, cultural awareness and expression. These key competencies are considered as necessary for employability in the knowledge society. Brunello and Schlotter (2011) show empirically that personality traits are important factors in that respect: They study the effect of personality traits on educa-

\footnotetext{
1 "Adult learning" and "lifelong learning" are used interchangeably in this paper.

${ }^{2}$ Eurostat; Adult Education Survey; Eurostat metadata; see http://epp.eurostat.ec.europa.eu

${ }^{3}$ Such as effort, cognitive ability or parental education.
} 
tional attainment, employment and wages. A positive aspect - especially for policy makers - is pointed out by Heckman (2000), who derives from the relevant psychological literature that non-cognitive skills continue to develop in contrast to cognitive skills which can be shown to be well set by the age of 8 . Non-cognitive skills are more malleable (Woessmann 2007: 62). Therefore - Heckman (2000) argues - it can be a promising policy alternative or complement to promote non-cognitive skills rather than cognitive skills. He further argues that "numerous instances can be cited of people with high IQ who fail to achieve success in life because they lacked self-discipline and of people with low IQ who succeeded by virtue of persistence, reliability and self-discipline ${ }^{4} "$. A recent article in the New York Times shows some interesting policy examples ${ }^{5}$.

We test the effect of several types of social capital on adult learning. First, we use measures inspired by the work of Granovetter (1973) who distinguishes in his notion of social capital between "weak ties" and "strong ties". Granovetter (1973) shows that acquaintances matter more for finding a job than strong friendships. We test this hypothesis in the context of adult learning. We then use more broad measures of social capital and test whether sociability and reciprocity determine the decision to participate in adult learning. Furthermore, we test the effect of the supportiveness of a social network. To measure adult learning we use three different indicators: attending professional courses, reading job-related literature and attending professional conventions or conferences. To address the econometric problem that individuals could meet friends during the professional class or convention, we use social capital variables that were measured before the class or conference was attended. In order to address the problem that time-variant factors such as a dynamic outlook on life could influence both social capital and adult learning we use a fixed-effects panel regression. In order to address the problem that there might also be time-variant factors influencing both social capital and adult learning we instrument the types of social capital with household's social capital. We use a novel econometric technique developed by Dong and Lewbel (2010) to address the problem that we have a discrete instrument.

We find that all types of social capital included in our paper have a significant and positive effect on adult learning. The size of the effect varies across the different measures between increasing the probability of participating in adult learning by $0.04 \%$ to increasing the probability by $17 \%$. Across all measures of adult learning we identified that one more unit of the perceived importance to be socially active increases the probability of participation in adult learning by the most $(17 \%)$ and that one additional friend increases this probability by the least $(0.04 \%)$. We also find that the supportiveness of the social network increases the probability of participating in adult learning by nearly as much as an additional unit in the perceived importance to be politically and socially active. Finally, we find that sociability increases the probability by more than reciprocity. Our results suggest that Granovetter's (1973) theory of weak and strong ties not only holds for employment but also in the context of adult learning. Our results hold across the three different ways of addressing endogeneity and point in the same direction.

The paper is structured as follows: section 2 presents an overview of the existing liter-

\footnotetext{
${ }^{4}$ http://chronicle.uchicago.edu/040108/heckman.shtml

${ }^{5}$ http://www.nytimes.com/2011/09/18/magazine/what-if-the-secret-to-success-isfailure.html?_r=1\&seid=auto\&smid=tw-nytimes\&pagewanted=all
} 
ature, in section 3 we present the data, in section 4 we analyze some descriptive statistics, section 5 discusses the results and section 6 concludes.

\section{Theoretical Background and Previous Findings}

In this section we review the literature on the relationship between educational outcomes and different types of social capital. We understand our paper as a contribution to the economic literature studying alternative determinants of education than the traditional ones assumed in human capital theory. There is a wide variety in understandings of the notion of "social capital" ranging from "connections" over "trust" to "political views" and consequently social capital is understood and measured in various ways: it can be measured as the number of friends (cf. Coleman 1988), the number of acquaintances (cf. Granovetter 1973), reciprocity (cf. Fehr and Gaechter 1988), trust (cf. Guiso et al. 2009), social activities and being sociable (cf. Betz 2008) or in its negative form of social disorders (cf. Carneiro et al 2007). Therefore, we understand that social capital can exist in different forms and social capital is understood as a concept capturing both the assets that measure the value of a network of an individual, a group or a society and the assets that make it easier to be in a social network.

Based on this definition, we interpret social capital as a form of personality traits and social capital is therefore seen as a non-cognitive skill (Borghans et al 2008, Bowles, Gintis and Osborne 2001 and Heckmann et al. 2006). Indeed, there is an increasing literature on the link between non-cognitive skills and education: non-cognitive skills are understood as a competence which is just as important as cognition for education. Wolfe and Johnson (1995); Duckworth and Seligman (2005) and Jacob (2002) show the link between non-cognitive skills and educational achievement. (Heckman, Rubinstein 2001) study a US program for school drop-outs showing that motivation and other non-cognitive skills rather than cognition seem to have determined the fact of dropping out of school at an early age. Illeris(2006) shows in a field experiment in Denmark that study psychological issues are important factors for successful lifelong learning. The non-cognitive skill "motivation" can further be linked to unemployment or being in an un-motivating low-skilled job (Rainbird 2001). Furthermore satisfaction or happiness can be linked to wanting to participate in training as Jones, Jones, Latreille, Sloane (2009) show. Identity is also linked to education as Akerlof and Kranton (2002 and 2009) argue. "Cultural capital" as a non-cognitive skill can also be a positive determinant of education in the case of minorities (Larsen and Istance 2001). However, the formation of oppositional identities such as the example of uneducated Afro-American neighborhoods) shows that identity can also have a negative effect on education (Akerlof and Kranton (2002). Holmlund and Silva (2009) provide evidence of the effects of policies targeting the improvement of non-cognitive skills: the authors examine the effect of a program conducted in an English secondary school to improve mainly self-confidence, locus of control, self-esteem and motivation on cognitive skills test outcomes. They do not find much evidence indicating the success of the policy in terms of literacy.

One of the most common understandings of social capital is that of connections, networks or peer groups. Bourdieu (1977, 1983 and 1986) - as one of the key thinkers in developing a theory of social capital - interprets social capital as potential resources that can be derived from being connected to a certain network. Coleman (1988) - a second important social 
capital theorist - understands social capital as a variety of attributes that help individuals who belong to a network. He shows that a higher level of social capital reduces the number of school drop-outs. Coleman (1994:300) argues that social capital can be an important factor for the development of adult as well as children's human capital. Putnam (1998 and 2000) a third important social capital theories - differs between bridging (heterogeneous contacts) and bonding (homogeneous contacts) forms of social capital and argues that education and social capital are linked by a virtuous circle (see Keeley 2007: 107). He proposes several measures how to increase social capital: civic courses, community service requirements and architectural considerations of how to encourage human intercourse in public buildings such as schools, offices and housing facilities. He argues that the closure of post offices can have a negative effect on the development of social capital. Sacerdote (2011) examines the role of peer effects in education from an economic point of view. Several scholars look at the role of social capital in form of social networks and learning using the term "lifelong learning" (cf. Field 2005, Strawn 2003, Schuller and Field 1998). Babcock (2008) finds that being part of a more socially connected cohort in a secondary or middle school is associated with significantly higher years of schooling attained and higher probability of having attained college 7 years later. Karweit, Hansell, and Ricks (1979) provide a review of the literature on how features of peer groups within schools affect the educational aspirations and achievements of their members. Schuller (2000) shows that social networks, the reciprocities arising from them and the value of these for achieving mutual goals - connected to school attainment, business innovation community development and social inclusion. Avis (2002) sees social connections are a vehicle for competitiveness and that they are highly connected to collective intelligence and expansive learning. De Giorgi and Pellerrazzi (2011) find that social interactions in form of mutual insurance matter for the performance of undergraduate students. Trade unions can also indicate a certain connection to a network. Maskell (2000) shows that connections, innovation and knowledge exchange are linked. Duncan and Stafford (1980), Mincer (1983) and Barron et al (1987) find negative effects of trade unions on education in the United States. Lynch (1992) finds a positive effect and further literature provide evidence for a positive relationship (for instance Rainbird 2001 and Bassanini et al 2005, chapter 3). A group of literature studies the effect of networks on the probability of employment (cf. Rees 1966, Bayer et al. 2008, Blau and Robbins 1990, Cingano and Rosolia 2006, Loury 2006, Calvo-Armengol and Jackson 2007 and Merlino 2011).

In economics trust and reciprocity is a definition of social capital that is often used. On the macroeconomic level there is a vast literature on the connection between interpersonal trust or systemic trust and the aggregate economic performance finding a positive and monotone relationship (see for example Butler et al. 2009: 4, Knack and Keefer 1997, Knack and Zak 2005 and Roth 2009). Guiso, Sapienza and Zingales (2009, 2010a, 2010b) see trust as a main factor determining the recent financial crisis. Dasgupta and Serageldin 2008 define systemic trust in a multi-faceted way and multiply the production function with their measure of trust. In behavioral economics, Fehr (2009) studies the role of trust for economic relations through its effect on preferences and beliefs. Fehr and Gaechter (1988) study the role of reciprocity in determining economic outcomes. Salisbury (1969) shows the economic importance of reciprocity by developing an "exchange theory of interest groups".

Social capital can also be interpreted as the result of an underlying personality trait sociability or social competence, which makes social capital more or less likely. Betz (2008) 
measures sociability by time spent with friends, family or acquaintances and the number of close friends. He uses an instrumental variable technique based on a measure of extraversion and an intergenerationally transmitted belief in whether people attempt to act helpful and finds that sociability increases earnings by about 8-10\%. Betz (2008) bases his analysis on Glaeser (2002) who argues that sociability is indeed a measure of social capital since it enables an individual to build a social network (Betz 2008:3).

Social capital is also viewed by some scholars as being characterized by "weak ties" or acquaintances and "strong ties" or friends: Granovetter (1973, 2005) makes a distinction between "weak ties" - those characterized as distant and by infrequent interaction (Levin 2002) and "strong ties" - strong friendships. There are two lines of argument supporting either weak or strong ties as the more important type of relationship for success in life. Granovetter argues that weak ties matter more for finding a job through a social network than strong ties. Weak ties are seen as those ties facilitating the transmission of information through the networks. In fact, the information that flows to individuals through weak ties is argued to be more novel than that flowing through the strong ties since the information in a close circle of friends is likely to be rather homogeneous. On the other hand, strong ties have been claimed important for success because they are more accessible and willing to be helpful (Krackhardt, 1992). In fact, many studies have shown that, overall, strong ties are of greater benefit to the receipt of useful knowledge (Ghoshal, Korine, \& Szulanski 1994, Szulanski 1996, Uzzi, 1996, 1997). Furthermore, there are noted benefits of strong ties for the receipt of useful knowledge (Levin 2004). In the same light it is argued that people with more strong ties are likely to have more education (Brinkerhoff et al. 2008). Granovetter (1983) also links social ties to the level of education and finds that there is an interaction effect between education and social ties in determining income.

Other forms of social capital that has been studied are the negative forms or effects of social capital. Roth and Thum (2010) for instance show on a macro level that too much social capital can hamper the PISA performance. Carneiro, Crawford and Goodman (2007) study the role that social skills play at the age of 11, using the National Child Development Survey (not exactly adults but gives insight already). They look mainly at social maladjustment shown through anxiety, nervousness or hostility towards other children and at the educational outcomes "stay on in school at age 16", "have a degree from a higher education institution at the age of 42 " and for a sub-sample "literacy and numeracy". They find that children which exhibited lower social adjustment or social disorders at the age of 11 were both less likely to stay at school beyond 16 and to have a lower final education degree. Results did not show any relation with cognitive skills at the age of 37 . Furthermore, they show that the effect of cognitive skills on the probability of staying at school beyond 16 is high when fixing social skills to a high level and low when fixing social skills to a low level. Social capital could also have a negative on training: for finding a job having friends or acquaintances could be a compensation for not participating in training (see van Alpen and Lancee 2008). Furthermore a social network can also have a negative impact on the probability to participate in training if the social network does not value education (see for example Keeley 2007:106). In our empirical analysis we will not look explicitly as these negative forms as analyzed by Crawford et al. (2007) since we see these factors as less relevant for understanding how individuals could be motivated to learn at adult age.

In the following section we will outline our own data source and methodology applied to 
study the relationship between social capital and adult learning.

\section{Data}

We use the German Socioeconomic Panel (SOEP), which is an annual household panel survey for Germany (see Wagner et al. 2007 and Frick et al. 2007 for details about the German SOEP). The first survey was conducted in 1984 and the most recent survey is available for 2009. Among the sampled households, every member above 17 is questioned. We primarily use the 2008 wave of the survey for the adult learning equation and add social capital variables from previous years, namely the 2003, 2004, 2005 and 2006 waves. As will be shown below, this is part of the estimation strategy to address endogeneity. The 2008 wave contains data on 19684 individuals living in about 11000 households.

We are interested in a sample of individuals that might enroll in further training, might attend conferences and would read scientific books or journals. With this end in mind we construct a sample that consists of 18-64 year old individuals, who are no longer in general school $^{6}$ and who are currently not at university, technical college or in vocational training. We restrict the sample to those who are full-time employed, part-time employed or not employed and drop those in military service, close to retirement or marginally employed. The sample size varies according to which measures are used between 8638 and 9704 observations.

In the waves 2000, 2004 and 2008 the SOEP contains special comparable questions on further training for adults - which we interpret as adult learning. We understand adult learning as the process of investing in activities to increase knowledge at adult age by the means of formal, non-formal and informal learning, outside universities in the sense of "further training". The following table shows these measures.

Table 1: Survey items for adult learning measures in the German socio-economic panel 2000, 2004 and 2008

\footnotetext{
${ }^{6}$ Gernal school includes secondary general school ("Hauptschule"), intermediate school ("Realschule"), upper secondary school ("Gymnasium"), comprehensive school ("Gesamtschule"), evening intermediate school ("Abendrealschule" and polytechnical high school ("Fachoberschule").
} 


\begin{tabular}{ll}
\hline Variable name & Survey item \\
\hline reading job-related lit- & "There are different opportunities available if one wants \\
erature & to educate himself further. Think back on the last three \\
& years. Have you in that time period done any of the \\
& following to further your professional education? - Reg- \\
& ularly read scientific or professional publications." \\
attending professional & "There are different opportunities available if one wants \\
courses & to educate himself further. Think back on the last three \\
& years. Have you in that time period done any of the fol- \\
& lowing to further your professional education? - Partici- \\
& pated in professionally oriented courses, including those \\
& which are still in progress." \\
"There are different opportunities available if one wants & to educate himself further. Think back on the last three \\
attending professional & years. Have you in that time period done any of the \\
following to further your professional education? - At- & tended professional conventions or congresses."
\end{tabular}

The SOEP also provides extensive information on social capital. As mentioned above, our understanding of social capital is broad and we understand that several different types of social capital exist. Therefore, our approach nests different definitions of social capital previously taken in the literature. It includes social networks (quality and quantity thereof), social values and beliefs and social character traits. Information on these types of social capital is given in the waves 2003, 2004, 2005 and 2006. The types of social capital included in our analysis are

- the number of friends: a measure of Granovetter's (1973) strong ties

- the perceived importance of being socially and politically active: a measure of Granovetter's (1973) weak ties

- a measure of the personality trait "sociability": This type of social capital is related to one dimension of the inventory of the Big Five personality traits (Costa and McCrae 1992). Glaeser (1992) defines social capital as an individual's social personality characteristics.

- a measure of the personality trait "reciprocity": This measure is related to trust and has been studied as a form of social capital in numerous economic studies (cf. Fehr and Gaechter 1988, Guiso et al. 2009,2010a, 2010b)

- a measure of the quality of the social network: The social network and its characteristics refer to a traditional understanding of social capital in sociology (cf. Bourdieu 1977, Coleman 1988, Putnam 2000)

The table below gives more detailed information on the variables used to measure these concepts and their construction.

Table 2: Corresponding theories for the social capital measures used from the German socio-economic panel 2003, 2004, 2005 and 2006 


\begin{tabular}{|c|c|c|}
\hline Measure of social capital & Corresponding theory & Survey item \\
\hline Number of friends & Granovetter (1973) & $\begin{array}{l}\text { "What would you say: How many close friends } \\
\text { do you have? " }\end{array}$ \\
\hline $\begin{array}{l}\text { Important to be socially } \\
\text { active }\end{array}$ & Granovetter (1973) & $\begin{array}{l}\text { "Is being socially and politically active currently } \\
\text { very important/important/less important/not } \\
\text { important at all for you?" }\end{array}$ \\
\hline Sociability & Glaeser (2002) & $\begin{array}{l}\text { For sociability we construct a latent scale us- } \\
\text { ing confirmatory factor analysis (principle fac- } \\
\text { tor method). We use the measures ( } 4 \text { indica- } \\
\text { tors): "I see myself as someone who is sociable, } \\
\text { outgoing." ( } 2005) \text {, "I see myself as someone who } \\
\text { is communicative, talkative." (2005), "I see my- } \\
\text { self as someone who is reserved" (reverse scal- } \\
\text { ing) (2005), "Do you meet friends, relatives or } \\
\text { neighbors during your free time?" (2005) }\end{array}$ \\
\hline Reciprocity & Fehr and Gaechter (1988) & $\begin{array}{l}\text { To measure reciprocity we compute a reciprocity } \\
\text { scale using confirmatory factor analysis (princi- } \\
\text { ple factor method) extracting a single scale. We } \\
\text { use the measures ( } 4 \text { indicators): "I see myself } \\
\text { as someone who has a forgiving nature" (2005), } \\
\text { "If someone does me a favor, I am prepared } \\
\text { to return it" ( } 2005 \text { ), "I go out of my way to } \\
\text { help somebody who has been kind to me be- } \\
\text { fore" (2005), "I am ready to undergo personal } \\
\text { costs to help somebody who helped me before" } \\
(2005)\end{array}$ \\
\hline Network & $\begin{array}{l}\text { Coleman (1988), Bour- } \\
\text { dieu (1973), Putnam } \\
(1998)\end{array}$ & $\begin{array}{l}\text { We construct a scale named "information net- } \\
\text { work" Lancee and van Alpen (2011). This } \\
\text { scale assesses whether individuals' environment } \\
\text { is likely to be supportive - by measuring educa- } \\
\text { tion and employment level of friends. We use } 7 \\
\text { indicators: "Please think of three people outside } \\
\text { of your household who are important for you, } \\
\text { personally. Respond for the first, second and } \\
\text { third person." (2006), "Is person }[1,2,3] \text { in school } \\
\text { / professional training / tertiary education as } \\
\text { opposed to registered as unemployed/retired or } \\
\text { other/no answer?", "Has person }[1,2,3] \text { attained } \\
\text { at least an intermediate school degreen as op- } \\
\text { posed to lower education or no answer?", "Does } \\
\text { one of persons [1,2,3] support your advancement } \\
\text { in your career or educational training and fosters } \\
\text { your progress?" }\end{array}$ \\
\hline
\end{tabular}


Construction of social capital scales The number of friends and the perceived importance of being socially and politically active are measured by a single variable whereas sociability, reciprocity and the quality of the network are measured by a set of indicators, which are used to construct latent scales for each of the three concepts. The scales for measuring various types of social capital are constructed using confirmatory factor analysis based on the principle factor method extracting a single scale. We use the STATA-inbuilt routine for this computation, choosing the maximum likelihood estimation technique. The technique allows reducing a set of indicators to a single dimension - the latent factor - which is based on the common variation among the indicators and separated from the random variation. It allows to address problems of measurement error and to capture several dimensions of a concept. The maximum-likelihood methodology used to extract the latent factors is based on Rao's canonical factor method ${ }^{7}$, which is based on maximizing the determinant of the correlation matrix of the set of indicators by seeking the highest canonical correlation with the indicators.

\section{Descriptive Analysis}

In this section we show some selected descriptive statistics in order to get an overview of the empirical relation between social capital and adult learning in our dataset. A common critique of adult learning is that it only reaches those who are already highly skilled. We therefore show participation rates in adult learning broken down by the ISCED education level. In order to get a view of whether social capital has the same effect on participation in adult learning across educational levels, we also show scatter plots of the predicted probability and social capital (using the sociability scale) controlling for a set of socioeconomic background variables.

First, we show the responses to the three measures of adult learning broken down by educational attainment. Table 3 shows the total participation rates in attending professional courses, regularly reading professional literature and attending professional conventions. Participation is highest in regularly reading job-related literature with $42 \%$ and lowest in attending professional gatherings with $22 \%$. The tables further show a break-down of the participation in the three types of adult learning by educational level. The tables show that the percentages of participation by the low skilled in adult learning are lower than those of medium or highly educated but they are representative.

Table 3: Educational attainment and participation in adult education based on data from the German socio-economic panel 2008

\begin{tabular}{|c|c|c|c|c|}
\hline Educational attainment and participation in adult education & low & medium & high & total \\
\hline \hline Regularly reading professional literature & 17.26 & 31.76 & 68.14 & 42.22 \\
\hline Attending professional courses & 11.80 & 22.29 & 43.99 & 28.29 \\
\hline Attending conferences and conventions & 5.47 & 14.71 & 41.26 & 22.44 \\
\hline
\end{tabular}

The following graphs show the predicted probabilities of attending professional classes and the relationship with social capital measures given a set of controls. We control for age,

\footnotetext{
${ }^{7}$ see Rao (1955)
} 
gender, registered as unemployed, german nationality, marital status and education. We are interested in getting a first idea of the effect of social capital measured by sociability on participation in adult learning given a set of relevant controls. We break down the results by education levels in order to see whether the effect hold for different educational groups. The graphs show that the effect is positive given the control variables for all three education levels. By simply eyeballing the results we can see that the effect might be slightly higher for the low-skilled.

Figure 1: Scatter plot with fitted values of the predicted probability to attend a professional adult learning class and sociability given a set of controls for the low skilled

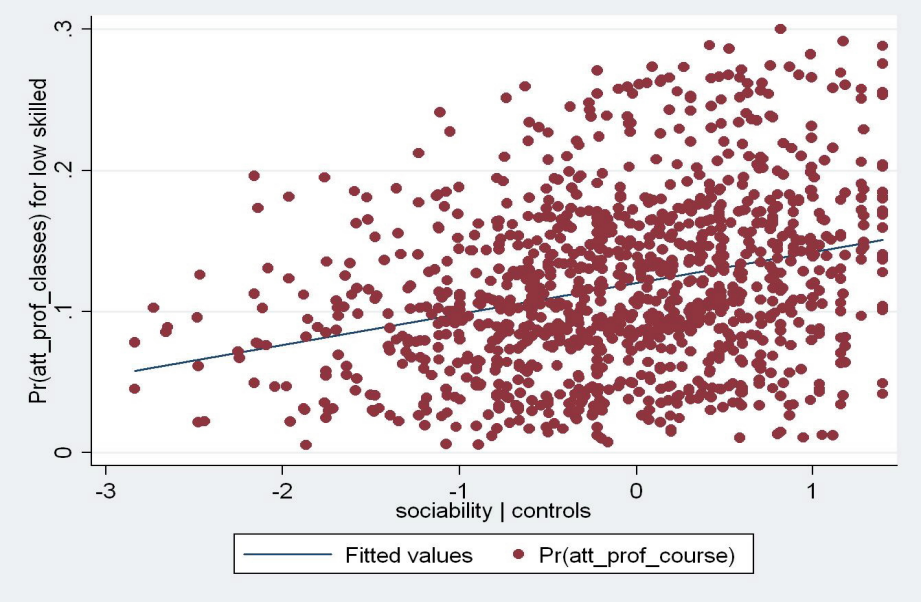


Figure 2: Scatter plot with fitted values of the predicted probability to attend a professional adult learning class and sociability given a set of controls for the medium skilled

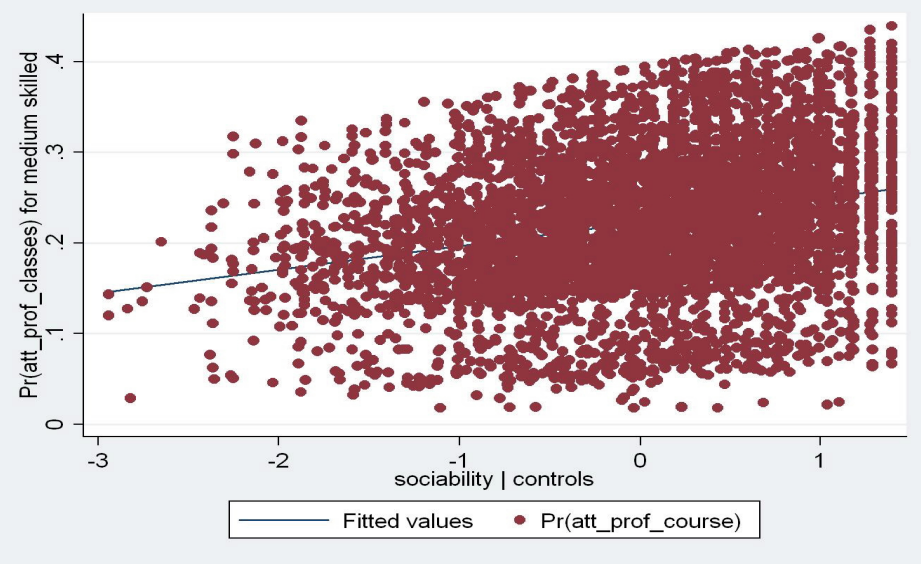

Figure 3: Scatter plot with fitted values of the predicted probability to attend a professional adult learning class and sociability given a set of controls for the high skilled

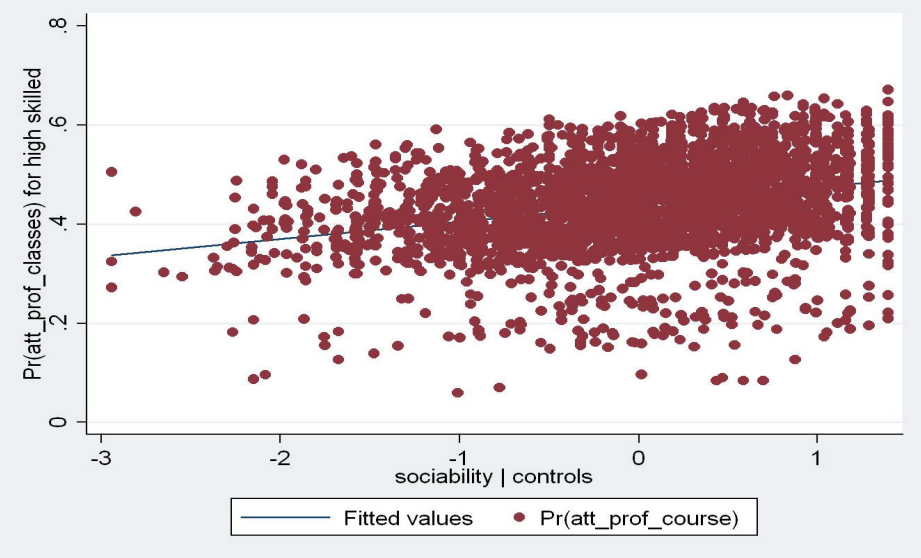




\section{Empirical Strategy}

A main econometric issue when studying the relationship between social capital and adult learning is the problem of endogeneity. In this paper we attempt to address three possible sources of endogeneity: (1) individuals can meet friends or become more sociable when participating in lifelong learning such as for instance by taking a professional class, (2) time-invariant factors can be correlated both with social capital and with lifelong learning such as deep personality traits such as a dynamic outlook on life and (3) time-varying unobserved factors can be correlated with social capital and with lifelong learning such as changing personality traits such as mood swings.

We apply a baseline probit model to the nationally representative German Socioeconomic Panel data. Consecutively we estimate a panel model and apply an instrumental variable procedure in order to test whether results are robust to different ways of addressing endogeneity. In the baseline probit model we address the first source of endogeneity named above - the problem that individuals might meet friends in their professional classes - by measuring the levels of social capital present before the adult learning. We call these measures "predetermined measures". Since the dependent variables are binary the regressions with predetermined measures are estimated with a classical probit estimator. The following baseline probit model is estimated:

$$
\begin{aligned}
& L_{i 08}=\left\{\begin{array}{c}
1 \text { if } L_{i 08}^{*}>0 \\
\text { otherwise }
\end{array}\right\} \\
& L_{i 08}^{*}=\alpha+\beta_{1} S_{i 08-s}+\beta_{2} X_{i 08}+\varepsilon_{i 08}
\end{aligned}
$$

where $L_{i 08}$ is a dummy variable indicating whether individual $i$ has participated in adult learning in 2008, $S_{i 08-s}$ is a measure of social capital that was either measured in 2003, 2004, 2005 or 2006 depending on the specific measure, $X_{i 08}$ is a set of control variables and $\varepsilon_{i 08}$ is a normally distributed error term. $\alpha$ denotes a constant intercept and $\beta_{1}$ and $\beta_{2}$ denote coefficients.

In a next step we construct a two-period panel data set and use a fixed-effects estimator that accounts for time-invariant factors correlated with both social capital and participation in adult learning. The panel data regressions are run using a fixed effects estimator for a linear probability model rather than a probit model in order to overcome incidental parameter problems (Wooldridge 2002). In a fixed effects probit model no sufficient statistic exists for estimation of the fixed effects. It is therefore not possible to condition the fixed effects out of the likelihood function (Stewart 2005). A logit model would be a potential alternative but would not allow estimating marginal effects. A potential alternative would be to use the Chamberlain-Mundlak device which is an unobserved effects probit model under strict endogeneity (Wooldridge 2009). This approach should be interpreted as a random effects procedure but imposes the assumption that the individual effects and the covariates are independent given time averages of $X_{i}$. We do not see this as a viable alternative since we need to make this additional assumption and therefore estimate a linear probability model. The main disadvantage of using a linear probability model in the context of binary variables is that the predicted probability might lie outside the unit interval, which is a smaller problem than the problem of non-identification and which we interpret as a smaller constraint than a 
strong independence assumption. Standard errors are estimated using the derived variance estimator for generalized least squares regression.

$$
P\left(L_{i t}^{*}=1 \mid S_{i t}, X_{i t}\right)=c+\alpha_{i}+\beta_{1} S_{i t t}+\beta_{2} X_{i t}+\varepsilon_{i t}
$$

In a third step, we apply an instrumental variable approach to control additionally for time-varying factors correlated both with social capital and life-long learning. We instrument the variables "number of friends" and "importance of being socially and politically active" by the household's number of friends and the household's belief in the importance of being socially and politically active. Concerning the strength of the instrument, we rely on an extensive literature on how the households' cultural, human and financial capital affects children's education. We argue that the household's social capital as part of the general capital that the household transmits to its members is a strong instrument for social capital. Concerning the exclusion restriction, we argue that the household members do not take part in the same adult learning class as the respective individual and their social capital can therefore not be directly correlated to elements that the respective individual learns or experiences at the adult learning class.

For the construction of the instrumental variable we construct mean social capital of the household as instrument. The household mean or median is calculated taking the respective individual out of the mean or median calculation and single households are dropped. We construct the median for categorical variables since these categories do not have a numerical meaning and the mean is therefore not a meaningful statistic whereas the median is since the categories are ordinal. For estimation we use a control function approach for discrete choice models with instrumental variables for continuous endogenous regressors. This approach is based on a maximum likelihood STATA inbuilt routine "ivprobit".

$$
\begin{aligned}
L_{i 08} & =\left\{\begin{array}{c}
1 \\
\text { if } L_{i 08}^{*}>0 \\
\text { otherwise }
\end{array}\right\} \\
L_{i 08}^{*} & =\alpha+\beta_{1} \hat{S}_{i 08-s}+\beta_{2} X_{i 08}+\varepsilon_{i 08}
\end{aligned}
$$

where $\hat{S}_{i 08-s}$ is an instrumental variable measure for social capital.

We cannot use the "ivprobit" routine for discrete choice models with discrete instrumental variables (instrumenting discrete items) and we therefore use an estimator developed by Dong and Lewbel $(2010,2012)$ in these cases. This approach addresses several problems

- with maximum likelihood estimators: the problem of parametric restrictions

- with control function approaches: the problem of consistency only if the endogenous regressors are continuously distributed

- with linear probability models: the problem that predicted probability lies outside the unit interval.

Lewbel (2011) outlines advantages and disadvantages of each of the cited methods. The methodology proposed by Dong and Lewbel $(2010,2012)$ does not require numerical searches 
nor correct functional forms of the endogenous regressors. Furthermore, probit and logit models can be interpreted as special cases of their estimator. However, the estimator requires that one exogenous regressor is conditionally independent of the model's error term and continuously distributed with a large support .

\section{Results}

In this section we test our underlying hypothesis that social capital is a positive force for educational outcomes. We examine the size of this effect and we analyze the difference in this effect across different types of social capital: a measure of weak ties, a measure of strong ties, a measure of sociability, a measure of reciprocity and a measure of the composition of the social network.

We perform three different types of econometric analyses and present their results: as explained in section 4 we start out with results using predetermined measures of social capital to address the problem that individuals could change their levels of social capital during the participation in lifelong learning. These results could be biased since there might be a timevariant underlying factor explaining both social capital and lifelong learning. A fixed-effects panel regression can address this problem. However, these results could again be biased since there might be a time-variant factor correlated both with social capital and lifelong learning. We address this problem by using an instrumental variable technique.

Tables 4-6 show the results using measures of social capital from before 2008 and lifelong measures from 2008. In this way we can measure the amount of social capital that was present before the lifelong learning class was taken. These measures may well still be correlated with other unobserved factors which are correlated with lifelong learning and with the social capital measures but they are not likely to be correlated with whatever happened in the lifelong learning class as they are predetermined in time. The tables show results from a classical probit regression with various types of social capital entering one at a time. We are adding the types of social capital once at a time since we are interested in the effects of each type of social capital, which we have derived from the theory and previous findings. In the last column of each of the Tables 4-6 we add all measures together in order to adress the problem of endogeneity which might arise through the fact that each measure can be interpreted as an omitted variable in a regression using a different measure. The results for the regression using all measures at once show that the measures that are highly significant on their own stay significant whereas those that are not or weakly significant are not significant any longer. F-tests ${ }^{8}$ indicate that the coefficients of all measures are not likely to be jointly equal to zero. In other words, the analysis including all measures at once confirms the results found when including one measure at a time.

The results show that all five measures of social capital have a significant impact on the participation in the three types of lifelong learning; apart from reciprocity which does not seem to have a significant effect on the probability of attending professional classes. Finding it important instead of less important to be socially and politically active increases the probability of participating in professional classes by 5 percentage points, which is about one fourth of the effect of being highly educated rather than medium educated. At the same

\footnotetext{
${ }^{8}$ For all three regressions of "attending courses", "regularly reading books" and "attending conferences".
} 
time it is around a third of the effect of being registered as employed rather than unemployed. The effect of having an additional friend when having the mean number of friends is smaller than the effect of finding it important instead of less important to be socially and politically active: having one more friend increases the probability of participating in professional classes by 0.2 percentage points. Being by one unit more sociable increases the probability to participate in professional classes by around 3 percentage points, which is about half of the effect of finding it important rather than less important to be socially active. This is around one tenth of the effect of being highly educated rather than medium educated. The effect of one more unit of supportiveness of the network has an effect similar in size to the effect of finding it important instead of less important to be socially and politically active. It is about half as important to have one more unit of supportiveness of the network than to be highly educated rather than medium educated.

The results for "regularly reading scientific journals" are similar but the coefficients of the social capital measures are slightly larger than for "attending professional classes": Finding it important instead of less important to be socially and politically active increases the probability of participating in professional classes by 10 percentage points, which is about one third of the effect of being highly educated rather than medium educated. Having one more friend at the mean number of friends is associated with an increase in the probability of reading scientific journals 0.6 percentage points which is about half the effect of finding it important instead of less important to be socially and politically active. Being one more unit more sociable has about half the effect of finding it important instead of less important to be socially and politically active and about a sixth of the effect of being highly educated rather than medium educated. Being one unit more reciprocal increases the probability of reading scientific journals by about one tenth of the effect of finding it important instead of less important to be socially and politically active while having a network which is one unit more supportive increases the probability of reading scientific journals by nearly as much as finding it important instead of less important to be socially and politically active.

The results for "attending conferences" again display the same signs. The size of the effect of finding it important instead of less important to be socially and politically active is about one fourth of the effect of being highly educated and rather than medium educated. The effect of having one more friend is about a tenth as big. Among the constructed scales the effect of one more unit of supportiveness of the social network is larger with respect to the effects of one more unit of sociability or reciprocity.

Using the percentages in Table 3 in the section on descriptive statistics, we can calculate the comparative importance of the measures of social capital across the different measures of lifelong learning. Finding it important instead of less important to be socially and politically active increases the probability of reading scientific literature by $17 \%$ whereas it increases the probability of participating in professional classes only by $7 \%$. The percentage changes of all social capital measures are highest for "regularly reading scientific journals". This could indicate that social capital has the most important effect on lifelong learning of the type of reading at home: this could be due to the fact that individuals wish to participate in conversations with their friends. In fact, the coefficient on the supportiveness (in terms of education) of the network changes by $14 \%$ for regular reading whereas it only changes by $5.6 \%$ and $5.8 \%$ respectively for "attending professional classes" or "attending conferences". This is the second biggest difference in percentage changes after the difference in the effect 
of finding it important instead of less important to be socially and politically active on "regularly reading" compared to "attending professional classes". 
Table 1: Probit regressions of adult capital measured by "attending professional courses" on measures of social capital - marginal effects

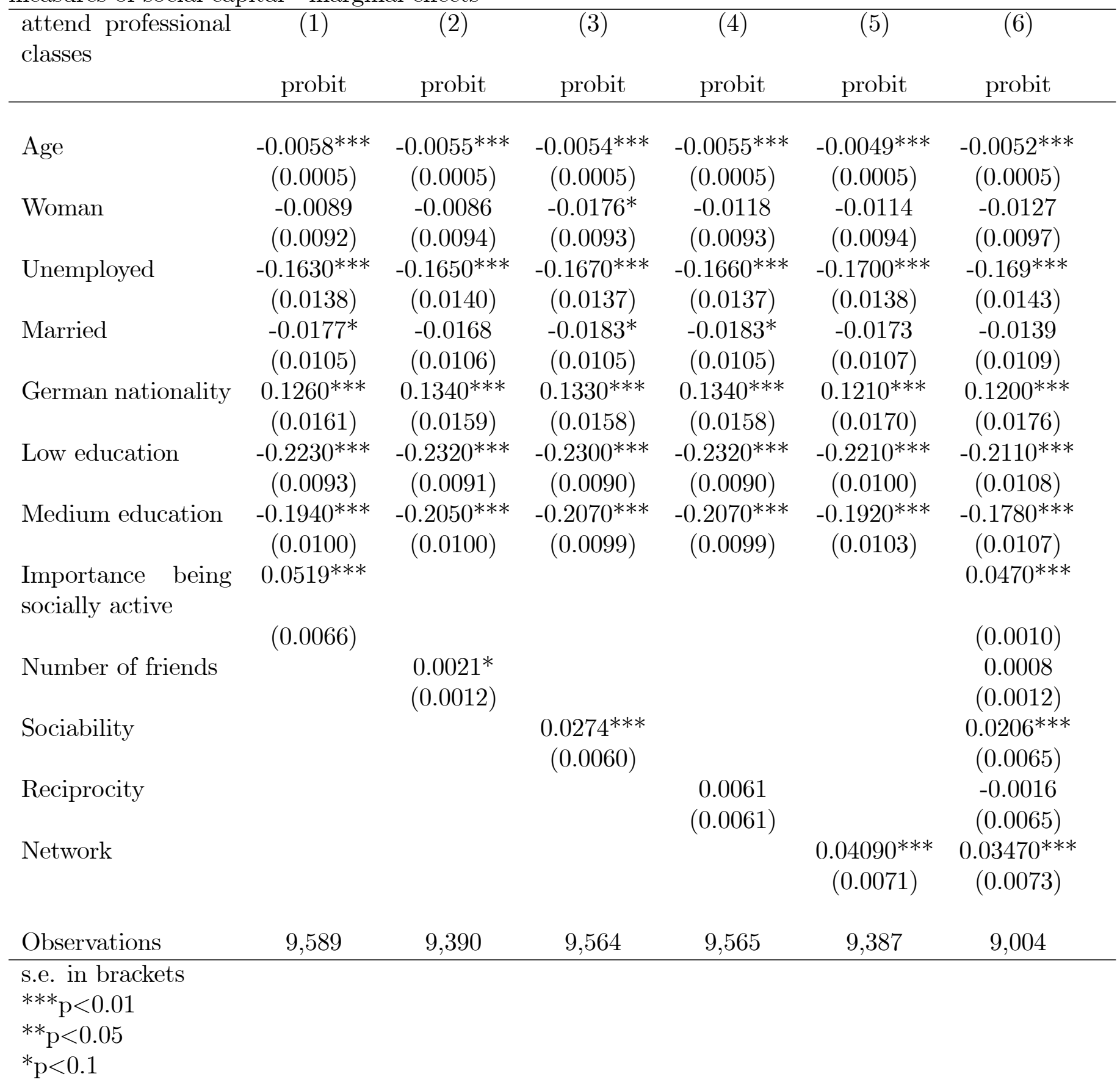


Table 2: Probit regressions of adult learning measured by "regularly reading scientific literature" and measures of social capital - marginal effects

\begin{tabular}{|c|c|c|c|c|c|c|}
\hline regularly read & $\begin{array}{c}(1) \\
\text { probit }\end{array}$ & $\begin{array}{c}(2) \\
\text { probit }\end{array}$ & $\begin{array}{c}(3) \\
\text { probit }\end{array}$ & $\begin{array}{c}(4) \\
\text { probit }\end{array}$ & $\begin{array}{c}(5) \\
\text { probit }\end{array}$ & $\begin{array}{c}(6) \\
\text { probit }\end{array}$ \\
\hline Age & $\begin{array}{c}-0.0025^{* * *} \\
(0.0005)\end{array}$ & $\begin{array}{c}-0.0018^{* * *} \\
(0.0005)\end{array}$ & $\begin{array}{c}-0.0017^{* * *} \\
(0.0005)\end{array}$ & $\begin{array}{c}-0.0020 * * * \\
(0.0005)\end{array}$ & $\begin{array}{c}-0.0009^{*} \\
(0.0006)\end{array}$ & $\begin{array}{c}-0.0014^{* *} \\
(0.0006)\end{array}$ \\
\hline Woman & $\begin{array}{c}-0.0989 * * * \\
(0.0108)\end{array}$ & $\begin{array}{c}-0.1010 * * * \\
(0.0109)\end{array}$ & $\begin{array}{c}-0.1170^{* * *} \\
(0.0109)\end{array}$ & $\begin{array}{c}-0.1040^{* * *} \\
(0.0108)\end{array}$ & $\begin{array}{c}-0.1040^{* * *} \\
(0.0109)\end{array}$ & $\begin{array}{c}-0.1100^{* * * *} \\
(0.0113)\end{array}$ \\
\hline Unemployed & $\begin{array}{c}-0.2030 * * * \\
(0.0185)\end{array}$ & $\begin{array}{c}-0.2200^{* * *} \\
(0.0182)\end{array}$ & $\begin{array}{c}-0.2150^{* * *} \\
(0.0180)\end{array}$ & $\begin{array}{c}-0.2140^{* * *} \\
(0.0180)\end{array}$ & $\begin{array}{c}-0.2190 * * * \\
(0.0181)\end{array}$ & $\begin{array}{c}-0.2210^{* * * *} \\
(0.0188)\end{array}$ \\
\hline Married & $\begin{array}{c}-0.04090^{* * *} \\
(0.0123)\end{array}$ & $\begin{array}{c}-0.04050^{* * *} \\
(0.0124)\end{array}$ & $\begin{array}{c}-0.0396 \text { *** } \\
(0.0123)\end{array}$ & $\begin{array}{c}-0.0389 * * * \\
(0.0123)\end{array}$ & $\begin{array}{c}-0.0373^{* * *} \\
(0.0125)\end{array}$ & $\begin{array}{c}-0.0386^{* * * *} \\
(0.0128)\end{array}$ \\
\hline German nationality & $\begin{array}{c}0.1760 * * * \\
(0.0204)\end{array}$ & $\begin{array}{c}0.1920^{* * * *} \\
(0.0200)\end{array}$ & $\begin{array}{c}0.1860^{* * *} \\
(0.0200)\end{array}$ & $\begin{array}{c}0.1870 * * * \\
(0.0199)\end{array}$ & $\begin{array}{c}0.1650 * * * \\
(0.0214)\end{array}$ & $\begin{array}{c}0.1580^{* * *} \\
(0.0223)\end{array}$ \\
\hline Low education & $\begin{array}{c}-0.3740 * * * \\
(0.0105)\end{array}$ & $\begin{array}{c}-0.3880 * * * \\
(0.0101)\end{array}$ & $\begin{array}{c}-0.3880 * * * \\
(0.0099)\end{array}$ & $\begin{array}{c}-0.3870 * * * \\
(0.0010)\end{array}$ & $\begin{array}{c}-0.3660 * * * \\
(0.0113)\end{array}$ & $\begin{array}{c}-0.3490^{* * *} \\
(0.0124)\end{array}$ \\
\hline Medium education & $\begin{array}{c}-0.3350 * * * \\
(0.0111)\end{array}$ & $\begin{array}{c}-0.3530 * * * \\
(0.0109)\end{array}$ & $\begin{array}{c}-0.3570 * * * \\
(0.0108)\end{array}$ & $\begin{array}{c}-0.3530 * * * \\
(0.0108)\end{array}$ & $\begin{array}{c}-0.3280 * * * \\
(0.0114)\end{array}$ & $\begin{array}{c}-0.3140^{* * *} \\
(0.0119)\end{array}$ \\
\hline $\begin{array}{l}\text { Importance being } \\
\text { socially active }\end{array}$ & $\begin{array}{c}0.1000^{* * *} \\
(0.0079)\end{array}$ & & & & & $\begin{array}{r}0.0889^{* * *} \\
(0.0083)\end{array}$ \\
\hline Number of friends & & $\begin{array}{c}0.0062^{* * *} \\
(0.0014)\end{array}$ & & & & $\begin{array}{c}0.0045^{* * *} \\
(0.0015)\end{array}$ \\
\hline sociability & & & $\begin{array}{c}0.0572^{* * *} \\
(0.0071)\end{array}$ & & & $\begin{array}{c}0.0422^{* * *} \\
(0.0076)\end{array}$ \\
\hline Reciprocity & & & & $\begin{array}{l}0.0159 * * \\
(0.0072)\end{array}$ & & $\begin{array}{c}0.0017 \\
(0.0076)\end{array}$ \\
\hline Network & & & & & $\begin{array}{c}0.0812^{* * *} \\
(0.0082)\end{array}$ & $\begin{array}{c}0.0735^{* * *} \\
(0.0084)\end{array}$ \\
\hline Observations & 9,279 & 9,090 & 9,255 & 9,255 & 9,102 & 8,734 \\
\hline $\begin{array}{l}\text { s.e. in brackets } \\
* * * \mathrm{p}<0.01 \\
* * \mathrm{p}<0.05 \\
{ }^{*} \mathrm{p}<0.1\end{array}$ & & & & & & \\
\hline
\end{tabular}


Table 3: Probit regressions of adult learning measured by "attending professional conferences and conventions" and measures of social capital - marginal effects

\begin{tabular}{|c|c|c|c|c|c|c|}
\hline attend conferences & $\begin{array}{c}(1) \\
\text { probit }\end{array}$ & $\begin{array}{c}(2) \\
\text { probit }\end{array}$ & $\begin{array}{c}(3) \\
\text { probit }\end{array}$ & $\begin{array}{c}(4) \\
\text { probit }\end{array}$ & $\begin{array}{l}(5) \\
\text { probit }\end{array}$ & $\begin{array}{c}(6) \\
\text { probit }\end{array}$ \\
\hline Age & $\begin{array}{c}-0.0025^{* * *} \\
(0.0004)\end{array}$ & $\begin{array}{c}-0.0022^{* * *} \\
(0.0004)\end{array}$ & $\begin{array}{c}-0.0021^{* * *} \\
(0.0004)\end{array}$ & $\begin{array}{c}-0.0023^{* * *} \\
(0.0004)\end{array}$ & $\begin{array}{c}-0.0018 * * * \\
(0.0004)\end{array}$ & $\begin{array}{c}-0.0020^{* * * *} \\
(0.0004)\end{array}$ \\
\hline Woman & $\begin{array}{c}-0.1060^{* * *} \\
(0.0084)\end{array}$ & $\begin{array}{c}-0.1080 * * * \\
(0.0085)\end{array}$ & $\begin{array}{c}-0.1150 * * * \\
(0.0085)\end{array}$ & $\begin{array}{c}-0.1090^{* * *} \\
(0.0084)\end{array}$ & $\begin{array}{c}-0.1100^{* * *} \\
(0.0085)\end{array}$ & $\begin{array}{c}-0.1120^{* * *} \\
(0.0087)\end{array}$ \\
\hline Unemployed & $\begin{array}{c}-0.1570 * * * \\
(0.0010)\end{array}$ & $\begin{array}{c}-0.1640^{* * *} \\
(0.0098)\end{array}$ & $\begin{array}{c}-0.1610^{* * *} \\
(0.0097)\end{array}$ & $\begin{array}{c}-0.1610^{* * *} \\
(0.0097)\end{array}$ & $\begin{array}{c}-0.1660^{* * *} \\
(0.0095)\end{array}$ & $\begin{array}{c}-0.1660^{* * * *} \\
(0.0097)\end{array}$ \\
\hline Married & $\begin{array}{c}0.0011 \\
(0.0095)\end{array}$ & $\begin{array}{c}0.0021 \\
(0.0096)\end{array}$ & $\begin{array}{c}0.0018 \\
(0.0095)\end{array}$ & $\begin{array}{c}0.0016 \\
(0.0095)\end{array}$ & $\begin{array}{c}0.0038 \\
(0.0096)\end{array}$ & $\begin{array}{c}0.0059 \\
(0.0098)\end{array}$ \\
\hline German nationality & $\begin{array}{c}0.1000^{* * *} \\
(0.0141)\end{array}$ & $\begin{array}{c}0.1100^{* * * *} \\
(0.0136)\end{array}$ & $\begin{array}{c}0.1060^{* * *} \\
(0.0137)\end{array}$ & $\begin{array}{c}0.1080^{* * *} \\
(0.0136)\end{array}$ & $\begin{array}{c}0.0957^{* * *} \\
(0.0150)\end{array}$ & $\begin{array}{c}0.0967^{* * *} \\
(0.0152)\end{array}$ \\
\hline Low education & $\begin{array}{c}-0.2030 * * * \\
(0.0064)\end{array}$ & $\begin{array}{c}-0.2100^{* * *} \\
(0.0063)\end{array}$ & $\begin{array}{c}-0.2090^{* * *} \\
(0.0062)\end{array}$ & $\begin{array}{c}-0.2080^{* * *} \\
(0.0062)\end{array}$ & $\begin{array}{c}-0.2010^{* * *} \\
(0.0068)\end{array}$ & $\begin{array}{c}-0.1930^{* * *} \\
(0.0072)\end{array}$ \\
\hline Medium education & $\begin{array}{c}-0.2110^{* * *} \\
(0.0092)\end{array}$ & $\begin{array}{c}-0.2240^{* * *} \\
(0.0092)\end{array}$ & $\begin{array}{c}-0.2250^{* * *} \\
(0.0091)\end{array}$ & $\begin{array}{c}-0.2230^{* * *} \\
(0.0091)\end{array}$ & $\begin{array}{c}-0.2070 * * * \\
(0.0095)\end{array}$ & $\begin{array}{c}-0.1990^{* * *} \\
(0.0098)\end{array}$ \\
\hline $\begin{array}{l}\text { Importance being } \\
\text { socially active }\end{array}$ & $\begin{array}{c}0.0519 * * * \\
(0.0060)\end{array}$ & & & & & $\begin{array}{c}0.0440^{* * *} \\
(0.0062)\end{array}$ \\
\hline Number of friends & & $\begin{array}{c}0.0041^{* * *} \\
(0.0011)\end{array}$ & & & & $\begin{array}{c}0.0029 * * * \\
(0.0011)\end{array}$ \\
\hline Sociability & & & $\begin{array}{c}0.0307^{* * * *} \\
(0.0055)\end{array}$ & & & $\begin{array}{c}0.0200^{* * *} \\
(0.0059)\end{array}$ \\
\hline Reciprocity & & & & $\begin{array}{c}0.0221^{* * * *} \\
(0.0057)\end{array}$ & & $\begin{array}{l}0.0138^{* *} \\
(0.0060)\end{array}$ \\
\hline Network & & & & & $\begin{array}{c}0.0451^{* * *} \\
(0.0066)\end{array}$ & $\begin{array}{c}0.0422^{* * *} \\
(0.0067)\end{array}$ \\
\hline Observations & 9,176 & 8,986 & 9,151 & 9,149 & 8,999 & 8,638 \\
\hline
\end{tabular}


Table 7 shows the results from a two period fixed effects panel regression. These measures are not correlated with time-invariant unobserved factors which are potentially related to lifelong learning and with the social capital measures - such as deep personal traits like a dynamic outlook on life - but they may well still be correlated with time-variant factors. We use the social capital measures "important to be socially and politically active" and "number of friends" since these social capital variables are available in two periods (2004 and 2008). As above, in columns (3), (6) and (9) we add all measures together in order to adress the problem of endogeneity which might arise through the fact that each measure can be interpreted as an omitted variable in a regression using a different measure. As above, the results for the regression using all measures at once show that the measures that are highly significant on their own stay significant whereas those that are not or weakly significant are not significant any longer. F-tests ${ }^{9}$ indicate that the coefficients of all measures are not likely to be jointly equal to zero. In other words, the analysis including all measures at once confirms the results found when including one measure at a time.The results from the previous regressions still hold and coefficients of both indicators are positive and significant in all equations with the exception of the number of friends in the equation of "attending conferences". This indicates that there is an effect of social capital on lifelong learning even when controlling for time-invariant factors such as deep character traits or parental upbringing. On average across individuals, a positive change over time in the number of friends by one unit, increases the probability of participating in professional classes in 2008 by 0.3 percentage points whereas a change over time in finding it important in instead of less important to be socially and politically active increases the probability by 2.4 percentage points. The size of the latter effect is around one fifth of the effect of being highly educated rather than medium educated. In terms of the probability to attend conferences, a change over time in finding it important in instead of less important to be socially and politically active increases the probability by 1.8 percentage points, which is around one tenth of the size of the effect of being highly educated rather than medium educated.

As a next step we instrument the measures of "own social capital" by "mean number of friends" and "median of the perceived importance of being socially and politically active" of the household. The results are displayed in Table 8. These measures are likely to be not correlated with any factors (time-variant or time-invariant) affecting both the error term and the instrumented social capital. As outlined in Section 4 we use an instrumental variable technique for probit models based on the control function approach for continuous endogenous regressors (the in-built STATA routine "ivprobit") and an estimator developed by Lewbel and Dong (2010, 2012) for probit models with discrete endogenous regressors. We use the latter for analyzing the effect of the perceived importance of being socially and politically active since it is a discrete variable. The instrumental variable probit model technique ("ivprobit") is not appropriate for discrete choice models with discrete endogenous instruments. As above, in columns (3), (6) and (9) we add all measures together in order to adress the problem of endogeneity which might arise through the fact that each measure can be interpreted as an omitted variable in a regression using a different measure. As above, the results for the regression using all measures at once show that the measures that are highly significant on their own stay significant whereas those that are not or weakly

\footnotetext{
${ }^{9}$ For all three regressions of "attending courses", "regularly reading books" and "attending conferences".
} 


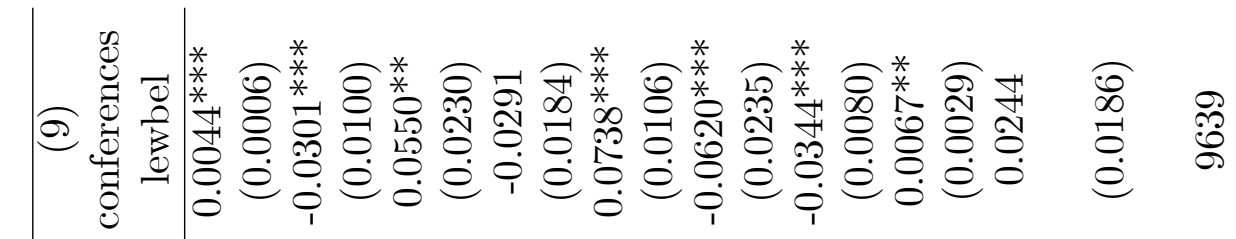

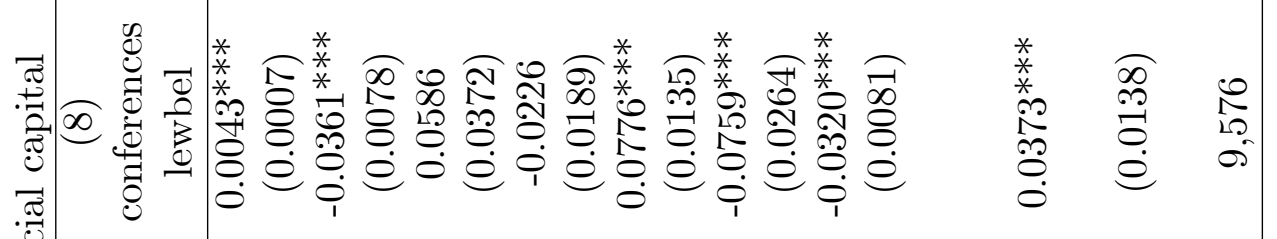

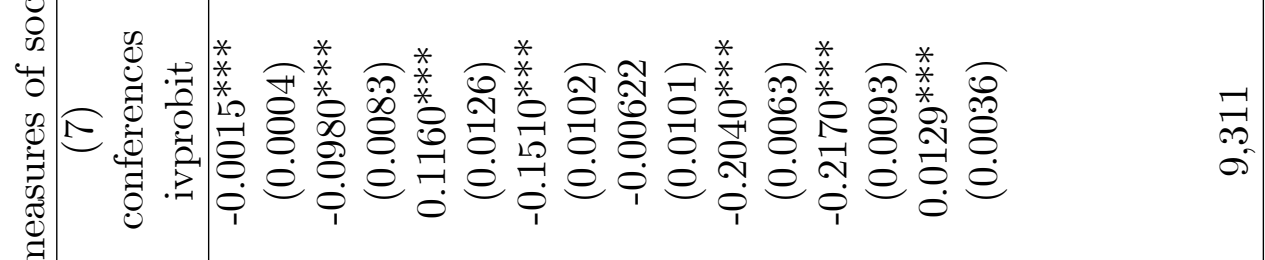

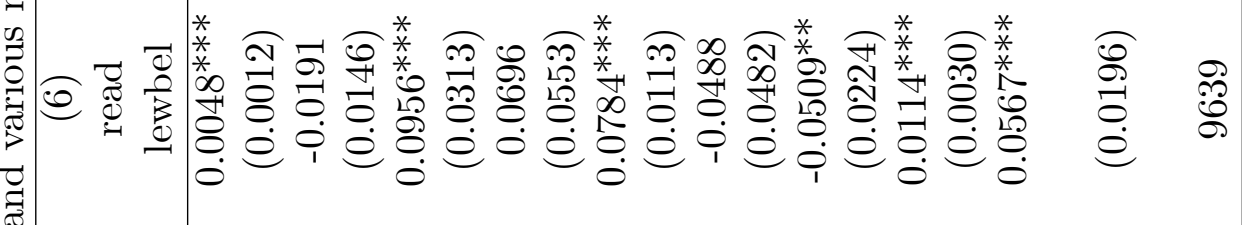

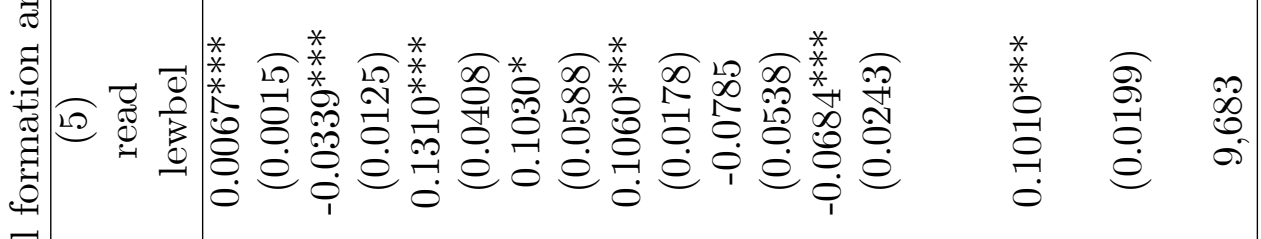

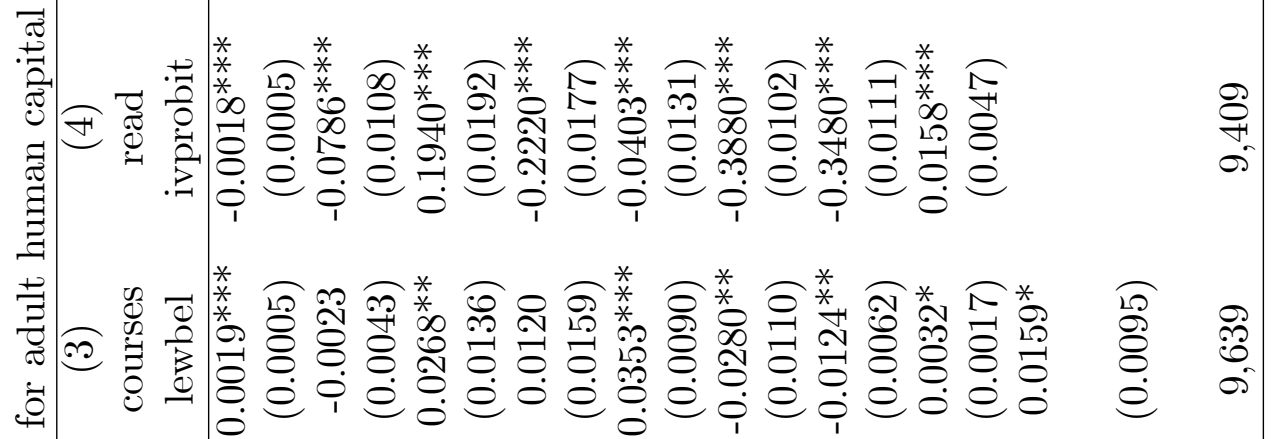

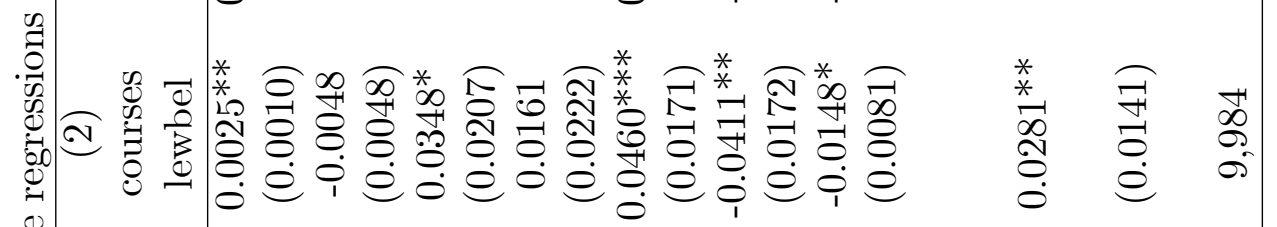

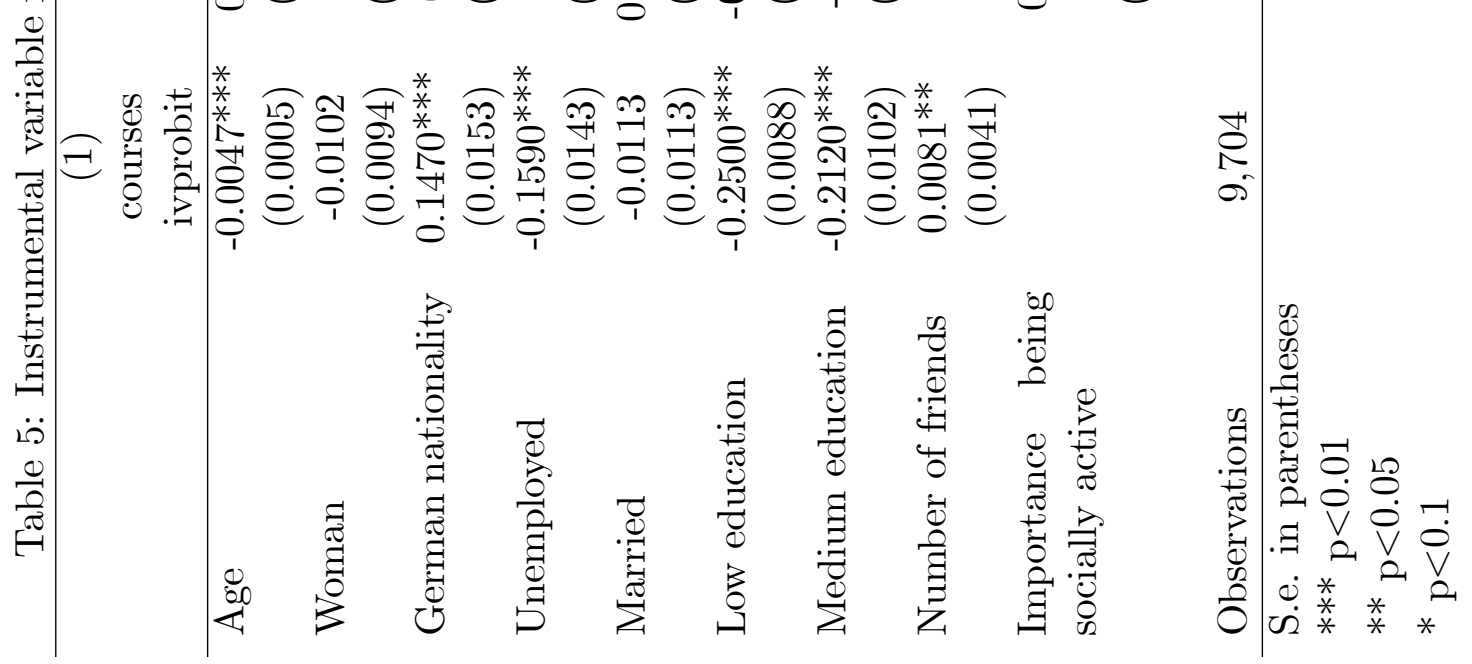


significant are not significant any longer - apart from the effect of the "perceived importance of being socially and politically active" for attending conferences (column (9)): in this case the coefficient looses its significance once we include both measures of social capital and only the effect of the number of friends stays significant. F-tests ${ }^{10}$ indicate that the coefficients of all measures are not likely to be jointly equal to zero. In other words, the analysis including all measures at once confirms the results found when including one measure at a time.

The results still hold and the effects of the number of friends as well as finding it important to be politically and socially active have a positive and significant effect on all three measures of lifelong learning. Just as the previous results, the instrumental variable results show that both social capital measures have the strongest effects on "regularly reading"11. The second strongest effects are those on "attending conferences" and the weakest are those on "attending professional classes".

Our results show that social capital matters and that different forms of social capital matter for different types of lifelong learning. The result holds when addressing various sources of endogeneity. Furthermore, our results show that the size of the effects varies across the different measures. The largest effect seems to be the effect of perceptions of the importance to be socially and politically active on the probability to regularly read scientific journals. The size of the effect varies across the different measures between increasing the probability of participating in adult learning by $0.04 \%$ to increasing the probability by $17 \%$. Across all measures of adult learning we have identified that increasing the perceived importance to be socially active by one unit increases the probability of participation in adult learning by the most (17\%) and one additional friend by the least (0.04\%). This result suggests that Granovetter's (1973) theory of weak and strong ties not only holds for employment but also in the context of adult learning. The supportiveness of the social network increases the probability of participating in adult learning by nearly as much as an additional unit in the perceived importance to be politically and socially active. Sociability increases the probability by more than reciprocity. Furthermore, different measures of social capital have the largest effects on the type of lifelong learning to read scientific journals and documents. One reason for this could be the wish to keep up with the one's social environment by being informed.

\section{Conclusion}

We set out to investigate the relationship between various types of social capital and adult learning empirically. We estimated the size of this relation and whether different types of social capital have different relations with adult learning. Even though common sense supports a positive and significant relationship between social capital and learning, the nature of this relationship is not quite so straightforward and needs to be empirically analyzed. This paper is the first to our knowledge that tests empirically the effects of different types of social capital on adult learning.

We examined the effects of a measure of strong ties, weak ties, sociability, reciprocity and supportiveness of the network using various techniques to address potential endogeneity:

\footnotetext{
${ }^{10}$ For all three regressions of "attending courses", "regularly reading books" and "attending conferences".

${ }^{11}$ This result is derived in terms of the percentage changes when using the percentages in tables 1-3.
} 
predetermined measures, panel data and instrumental variable techniques. To address the econometric problem that individuals could meet friends during the professional class or convention, we use social capital variables that were measured before the class or conference was attended. In order to address the problem that time-variant factors such as a dynamic outlook on life could influence both social capital and adult learning we use a fixed-effects panel regression. In order to address the problem that there might also be time-variant factors influencing both social capital and adult learning we instrument the types of social capital with household's social capital. We use a novel econometric technique developed by Dong and Lewbel (2010) to address the problem that we have a discrete instrument.

We find that all types of social capital included in our paper have a significant and positive effect on adult learning. The size of the effect varies across the different measures between increasing the probability of participating in adult learning by $0.04 \%$ to increasing the probability by $17 \%$. Across all measures of adult learning we have identified that increasing the perceived importance to be socially active by one unit increases the probability of participation in adult learning by the most (17\%) and one additional friend by the least (0.04\%). This result suggests that Granovetter's (1973) theory of weak and strong ties not only holds for employment but also in the context of adult learning. The supportiveness of the social network increases the probability of participating in adult learning by nearly as much as an additional unit in the perceived importance to be politically and socially active. Sociability increases the probability by more than reciprocity. Our results hold across the three different ways of addressing endogeneity and point in the same direction.

The empirical evidence should make policy makers planning lifelong learning policies aware of an existing relationship between social capital and adult learning. This relationship could imply that it makes a difference as to which neighborhood or social context a lifelong learning policy is applied. As the results on the effect of the "information network" on lifelong learning show, there seems to be a peer effect in actual attendance of the classes: individuals with a more education-friendly network might be motivated by their network to keep up with their network. This fact could be useful for policy makers in that they should understand that mixed neighbourhoods and proximity of institutions (for instance clubs, community centers and more) could be a more favorable environment for lifelong learning. Putnam's (Keeley 2007) suggestion of protecting local bakeries and post offices as meeting places could be useful. Furthermore, when counseling and assisting individuals in terms of their education and success in life it should be taken into account that the dimensions of social capital assessed in this paper play a role. An individual with one network of friends might not have the same values and beliefs as another. These issues apply particularly to migrants, who might face difficulties in building their network in the host country. 


\section{Appendix}

\subsection{Summary Statistics}

Table 6: Summary statistics

\begin{tabular}{lccc}
\hline \multicolumn{1}{c}{ Variable } & Mean & Std. Dev. & N \\
\hline Unemployed & 0.074 & 0.262 & 9637 \\
Read job-related literature & 0.422 & 0.494 & 9325 \\
Attend conferences & 0.224 & 0.417 & 9219 \\
Attend professional courses & 0.283 & 0.45 & 9637 \\
German nationality & 0.932 & 0.252 & 9637 \\
Woman & 0.513 & 0.5 & 9637 \\
Age & 45.823 & 10.654 & 9637 \\
Married & 0.672 & 0.47 & 9637 \\
Importance being socially active & 2.921 & 0.718 & 9589 \\
Number of friends & 4.601 & 3.957 & 9390 \\
Sociability & 0 & 0.79 & 9564 \\
Reciprocity & 0 & 0.762 & 9565 \\
Network & 0 & 0.733 & 9387 \\
Low education & 0.118 & 0.322 & 9637 \\
Medium education & 0.549 & 0.498 & 9637 \\
High education & 0.333 & 0.471 & 9637 \\
\hline
\end{tabular}




\section{References}

[1] Akerlof, G. and Kranton, R. 2011. "Identity Economics: How our Identities affect our Work, Wages and Well-Being." Journal of Economics 104: 95-97.

[2] Akerlof, G. and Kranton, R. 2009. Identity Economics: How Our Identities Shape Our Work, Wages, and Well-Being. Princeton: Princeton University Press.

[3] Avis, J. 2002. "Social Capital, Collective Intelligence and Expansive Learning: Thinking through the Connections. Education and the Economy." British Journal of Educational Studies 50 (3): 308-326.

[4] Babcock P. 2008. "From Ties to Gains? Evidence on Connectedness and Human Capital Acquisition." Journal of Human Capital 2 (4):379-409.

[5] Barron, J.; D. Black and M. Loewenstein. 1987 "Employer Size: The Implications for Search, Training, Capital Investment, Starting Wages, and Wage Growth." Journal of Labor Economics 5: 76-89.

[6] Bassanini, A., A. L. Booth, G. Brunello, M. De Paola and E. Leuven. 2005. "Workplace Training in Europe.". In: Education and Training in Europe, edited by G. Brunello, R. Garibaldi and E. Wasmer. Oxford: Oxford University Press.

[7] Bayer P., Ross S. and G. Topa. 2008. "Place of work and place of residence: Informal hiring networks and Labor Market Outcomes." Journal of Political Economy, 116 (6):1150-1196.

[8] Betz, F. 2008. "Returns to sociability." Manuscript, European University Institute.

[9] Blau D. and P. Robins 1990. "Job Search. Outcomes for the Employed and Unemployed." Journal of Political Economy 98: 637-655.

[10] Borghans, L., A.L. Duckworth, J.J. Heckman and B. ter Weel. 2008. "The economics and psychology of personality traits." Journal of Human Resources 43 (4): 972-1059.

[11] Bourdieu, P. 1977. Outline of a Theory of Practice. Cambridge: Cambridge University Press.

[12] Bourdieu, P. 1983. "Ökonomisches Kapital, kulturelles Kapital, soziales Kapital." In Soziale Ungleichheiten (Soziale Welt, Sonderheft 2), edited by Reinhard Kreckel. Goettingen: Otto Schartz \& Co.

[13] Bourdieu, P. 1986. "The forms of capital." In Handbook of Theory and Research for the Sociology of Education, edited by J. Richardson. New York: Greenwood.

[14] Bowles S., Gintis H, and M. Osborne. 2001. "The Determinants of Earnings: A Behavioral Approach." Journal of Economic Literature 39 (4): 1137-1176.

[15] Brinkerhoff, D. Lynn K. White, Suzanne T. Ortega. 2008. Essentials of Sociology. Wadsworth: Thomson. 
[16] Brunello, G. and M. Schlotter. 2011. "Non-cognitive skills and personality traits: labour market relevance and their development in education and training Systems." IZA working paper No. 5743, Bonn: Institut fuer die Zukunft der Arbeit.

[17] Butler, J.; P. Giuliano and L. Guiso. 2009. "The right amount of trust", EIEF Working Papers Series No. 0908, Florence: European University Institute.

[18] Calvo-Armengol, A. and M. Jackson. 2007. "Networks in labour markets: wage and employment dynamics and inequality." Journal of Economic Theory 132: 27-46

[19] Carneiro P., Crawford C., and A. Goodman. 2007. "The impact of early cognitive and non-cognitive skills on later outcomes", CEE Discussion Papers No. 0092, London: Centre for the Economics of Education, London School of Economics.

[20] Cingano F. and Rosolia A. 2006. "People I Know, Workplace Networks and Job Search Outcomes." Bank of Italy working paper series No. 600, Rome: Bank of Italy.

[21] Coleman, J. 1988. "Social capital in the creation of human capital." American Journal of Sociology 94: 95-120.

[22] Coleman, J. C. 1994. Foundations of Social Theory. Cambridge, Mass.: Harvard University Press.

[23] Dasgupta, P. and Serageldin, I. 2000. Social Capital: A Multifaceted Perspective. Washington, D.C.: World Bank.

[24] De Giorgi, G. and Pellirazzi, M. 2011: "Understanding social interaction: evidence from the classroom". IZA working paper Nr. 5624, Bonn: Institut fuer die Zukunft der Arbeit.

[25] Dong Y., and Lewbel A. 2010: "Simple Estimators for bianary choice models with endogenous regressors." Manuscript, California State University Fullerton and Boston College.

[26] Dong Y., and Lewbel A. 2012: "Simple Estimators for bianary choice models with endogenous regressors." Manuscript, California State University Fullerton and Boston College.

[27] Duckworth, A. L., and Seligman, M. E. P. 2005. "Self-discipline outdoes IQ in predicting academic performance of adolescents." Psychological Science 16 (12): 939-944.

[28] Duncan, G. and Stafford, F. 1980. "Do Union Members Receive Compensating Wage Differentials?" American Economic Review 70 (June): 355-71.

[29] European Commission. 2006. "European Framework for Key Competences for Lifelong Learning." Brussels: European Commission.

[30] Fehr, E. and F. Gaechter (1988): "Reciprocity and economics: The economic implications of Homo Reciprocans." European Economic Review 42 (3-5): 845-859. 
[31] Fehr, E. 2009. "On the biology and economics of trust." Journal of the European Economic Association 7(2-3): 235-266.

[32] Field, J. 2005. Social capital and lifelong learning. Bristol: The Policy Press.

[33] Frick, Joachim R., Stephen P. Jenkins, Dean R. Lillard, Oliver Lipps, and Marc Wooden. 2007. The Cross-National Equivalent File (CNEF) and its Member Country Household Panel Studies. Schmollers Jahrbuch 127, no. 4, 627-654. http://www.diw.de/sixcms/detail.php/77260

[34] Fukuyama, F. 2007. "Social Capital and Development: The Coming Agenda." SAIS Review 22: 23-37.

[35] Ghoshal, K. and M. Szulanski. 1994. "Interunit Communication in Multinational Corporations." Management Science 40 (1): 96-110

[36] Granovetter, M. 1973. "The strength of weak ties." American Journal of Sociology 78: $1360-1380$.

[37] Granovetter, M. 2005. "The impact of social structure on economic outcomes." Journal of Economic Perspectives 19(1): 33-50.

[38] Guiso, L., P. Sapienza and L. Zingales. 2009. "Moral and Social Constraints to Strategic Default on Mortgages." NBER Working Papers Nr. 15145. Cambridge, Mass: National Bureau of Economic Research.

[39] Guiso, L., P. Sapienza and L, Zingales. 2010a. "Civic Capital as the Missing Link." Economics Working Papers ECO2010/08. Florence, European University Institute.

[40] Guiso, L. 2010b. "A trust-driven financial crisis. Implications for the future of financial markets." Economics Working Papers ECO2010/0\%. Florence: European University Institute.

[41] Heckman, J. 2000. Invest in the very young. Chicago: Ounce of Prevention Fund.

[42] Heckman, J. and Rubinstein, Y. 2001. "The importance of non-cognitive skills: Lessons from the GED testing program." American Economic Review 91 (2): 145-149.

[43] Heckman, J., J. Stixrud and S. Urzua. 2006. "The Effects of Cognitive and Noncognitive Abilities on Labor Market Outcomes and Social Behavior." Journal of Labor Economics 24(3): 411-482.

[44] Holmlund, R. and O. Silva. 2009. "Targeting Non-Cognitive Skills to Improve Cognitive Outcomes: Evidence from a Remedial Education Intervention." IZA Discussion Papers No. 4476. Bonn: Institut fuer die Zukunft der Arbeit.

[45] Illeris, K. 2006. "Lifelong learning and the low skilled." International Journal of Lifelong Learning 25 (1): 15-28. 
[46] Jacob, B. 2002. "Where are Boys aren't: Non-Cognitive Skills, Returns to School and the Gender Gap in Higher Education." Economics of Education Review 21(6): 589:598.

[47] Jones, M.; R. Jones, P. Latreille and P. Sloane. 2009. "Training, job satisfaction and workplace performance in Britain: evidence from WERS 2004." Labour 23: 139-175

[48] Karweit, N., S. Hansell and M. Ricks. 1979. "The Conditions for Peer Association in Schools." Manuscript, Center for Social Organization of Schools, Johns Hopkins University.

[49] Keeley, P. 2007. Human capital. How what you know shapes your life. Paris: OECD Insights.

[50] Knack, S. and P. Keefer. 1997. "Does Social Capital Have an Economic Payoff? A Cross-Country Investigation." Quarterly Journal of Economics 112(4): 1251-1288.

[51] Krackhardt, D. 1992. "The Strength of Strong Ties: The Importance of Philos in Organizations." In Networks and Organizations: Structure, Form, and Action, edited by Nitin Nohria and Robert Eccles. Boston: Harvard Business School Press.

[52] Larsen, K and Istance, D. 2001. Lifelong learning for all. Paris: OECD Observer.

[53] Levin. K. 2002. "The Strength of Weak Ties you can Trust: the Mediating Role of Trust in Effective Knowledge Transfer", under review Acadamy of Management Journal.

[54] Lewbel, A. 2011. "Binary Choice With Endogenous Or Mismeasured Regressors." Lecture Notes, Boston College, Dept. Econ.

[55] Loury L.D. "Some Contacts Are More Equal than Others: Informal Networks, Job Tenure, and Wages." Journal of Labor Economics 24(2): 299-318.

[56] Lynch, L. 1992. "Private-Sector Training and the Earnings of Young Workers." American Economic Review 82(1): 299-312.

[57] Maskell, P. 2000. "Social capital, innovation and competitiveness." In Social capital: Critical Perspectives, edited by S. Baron, J. Field and T. Schuller. Oxford: Oxford University Press.

[58] Merlino, L. and Galeotti, A. 2011. "Endogenous Job Contact Networks." ISER Working Paper Series No. 2010-14, Essex: Institute for Social and Economic Research.

[59] Mincer, J. 1983. "Union Effects: Wages, Turnovers and job Training." In Reserarch in Labor Economics, Supplement 2: New Approaches to Labor Unions, edited Joseph Reid, Greenwich, Conn.: JAI press.

[60] Polanyi, M. 1966. The Tacit Dimension. London: Routledge \& Kegan Paul.

[61] Portes, A. 1998. "Social capital: its origins and applications in modern sociology." Annual Review of Sociology 24: 1-24. 
[62] Putnam, R. 1995. "Bowling alone: America's declining social capital." Journal of Democracy 6: 65-78.

[63] Putnam, R. 2000. Bowling alone: The collapse and revival of American community. New York, NY: Simon and Schuster.

[64] Rainbird, H. Stuart, M. 2001. "The State and the Union Learning Agenda in Britain." Employment and Society 25 (June): 202-217.

[65] Rao, C.R. 1955. "Estimation and Tests of Significance in Factor Analysis." Psychometrika 20: 93-111.

[66] Rees, A. "Information Networks in Labor Markets." American Economic Review 56: 559-566.

[67] Roth, F. 2009. "Does too much trust hamper economic growth?" Kyklos 62(1): 103-128.

[68] Roth, F. and Thum, A. 2010. "The Key Role of Education in the Europe 2020 strategy." In The European Dimensions of Education Policy, edited by H. Schneider and J. de Groof, Maastricht: University of Maastricht.

[69] Sacerdote, P. 2011. "Peer effects in education: How might they work, how big are they and how much do we know thus far?" Handbook of Economics of Education, 3: 249-277.

[70] Salisbury, R. 1969. "An Exchange Theory of Interest Groups." Midwest Journal of Political Science 13(1): 1-32.

[71] Schuller, M. and Field, J. 1998. "Social capital, human capital and the learning society." International Journal of Lifelong Learning 17(4): 226-235.

[72] Schuller, T., Baron, S. and Field, J. 2000. "Social Capital: a review and critique." In Social Capital: critical perspectives, edited by Baron, S., Field, J., and Schuller, T. Oxford: Oxford University Press.

[73] Stewart, M. 2005. "Panel Data Models with Limited Dependent variables." Lecture Notes, Univerisity of Warwick, Dept. Econ.

[74] Strawn, C. 2003. "Social Capital Influences Of Lifelong Learning Among Adults Who Didn't Finish High School." Occasional Paper, National Center for the Study of Adult Learning and Literacy, Harvard Graduate School of Education.

[75] Szulanski, G. 1996. "Exploring internal stickiness: Impediments to the transfer of best practice within the firm." Strategic Management Journal 17(Winter Special Issue): $27-43$.

[76] Uzzi, B. 1996. "The Sources and Consequences of Embeddedness for the Economic Performance of Organizations." American Sociological Review 61:674-98

[77] Uzzi, B. 1997. "Social Structure and Competition in Interfirm Networks: The Paradox of Embeddedness." Administrative Science Quarterly 42:35-67 
[78] Van Alphen, S. and B. Lancee. 2008. "Compensating early school leave in Germany: the influence of social capital." Manuscript, European University Institute, Dept. Econ.

[79] Wagner, Gert G., Joachim R. Frick, and Jürgen Schupp. 2007. The German Socio-Economic Panel Study (SOEP) - Scope, Evolution and Enhancements. Schmollers Jahrbuch 127, no. 1, 139-169. http://schmollersjahrbuch.diw.de/schmollersjahrbuch/webcontent/2007/Wagner\%20et\%20al.pdf

[80] Woessmann,L. 2007. "School accountability, autonomy, choice and the level of student achievement: international evidence from PISA 2003", Report for the OECD on the project "The evaluation of the relationship between nation policies affecting school autonomy and parental choice". Paris: OECD.

[81] Wolfe,R.N., and Johnson,S.D. 1995. "Personality as a predictor of college performance." Educational and Psychological Measurement 55: 177-185.

[82] Wooldridge, J. 2002. Econometric analysis of cross section and panel data. Cambridge, Mass.: MIT Press.

[83] Wooldridge, J. 2009. "New developments in econometric. Nonlinear panel data models." Lecture Notes, University College London, Dept. Econ.

[84] World Bank. 1999. "What is social capital?" Washington: World Bank. 